\title{
RHEED INTENSITY OSCILLATIONS DURING THE GROWTH OF INDIUM ULTRATHIN FILMS
}

\author{
M. StrRóżaK, M. Jalochowski and M. Subotowicz \\ Department of Experimental Physics, Institute of Physics \\ Maria Curie-Skłodowska University \\ Pl. M. Curie-Skłodowskiej 1, 20-031 Lublin, Poland
}

(Received May 21, 1991)

\begin{abstract}
The ultrathin high-purity single-crystal indium films with atomically flat surfaces and precisely known thicknesses in UHV conditions were prepared. These films were deposited on the $\operatorname{Si}(111)-(7 \times 7)$ and $\operatorname{Si}(111)-(6 \times 6) \mathrm{Au}$ substrate cooled to temperatures up to $110 \mathrm{~K}$. The growth of the indium films wis studied by reflection high-energy electron diffraction (RHEED). Pronounced specular beam intensity oscillations are found. The consequences far the understanding of RHEED intensity oscillations and of the growth of utrathin films are discussed. The amplitude of the RHEED specular beam intensity oscillations as a function of the polar angle and temperature substrate Si was measured.
\end{abstract}

PAOS numbers: $61,11,-x_{1}, 68: 55 ;-2 a$

\section{Introduction}

Reflection high-energy electron diffraction (RHEED) is very useful technique for studying growth and surface analysis of thin epitaxial structures prepared by molecular beam epitaxy (MBE). In particular the technique RHEED intensity oscillations has been used to process control growth layers in MBE [1]. The phenomenon of RHEED intensity oscillations was first observed during homoepitaxial growth of the semiconductors $[2,3]$. In recent works the oscillations have been observed also during the growth of ultrathin metallic films with different lattice structure [4-6]. Oscillations in the intensity of RIIEED patterns, observed under normal growth conditions, can be explained by a two-dimensional nucleation-on-terraces growth mode.

The information obtained from RHEED patterns is of potentially very wide ranging [1]. One can obtain informations about steps, islands and deduce the surface structure. It is also possible to derive more quantitative information about the surface structure such as positions of the surface atoms. 
In this work we report the results of the RIIEED intensity oscillations study during growth of the metallic ultrathin indium films deposited on $\mathrm{Si}(111)$ surface. Diffracted electron beam intensity was analysed as a function of the diffraction parameters (azimuth, incidence angle and different substrate structures). The temperature dependence of the substrate on RHEED intensity oscillations was discussed. We show that the growth mode of In on the Si(111) surface can be modified by evaporation of the other elements. About 0.5 atomic percent of $\mathrm{Ag}$ remarkably prolonged the layer-by-layer growth of $\mathrm{Pb}$ [7]. The RIIEED rocking curve of the $\mathrm{Si}(111)$ surfaces was also measured.

\section{Experimental}

The ultrathin In films were prepared in an ultrahigh vacuum (UHV) system [8] pumped by an ion pump and Ti-sublimation pump with a liquid-nitrogen (LN)-cooled cold wall. The base pressure was better than $1 \times 10^{-10} \mathrm{hPa}$ and the pressure during deposition was kept below $4 \times 10^{-10} \mathrm{hPa}$. The substrates were Si(111.) wafers with about $6 \Omega \mathrm{cm}$ specific resistivity at room temperature and typical dimensions $18 \times 4 \times 0.6 \mathrm{~mm}$. They were etched in $19 \mathrm{HNO}_{3} \times 1 \mathrm{HF}$, rinsed in distilled water and methanol. After chemical etching the final surface cleaning was performed in the vacuum system before deposition by flashing for a few seconds at about $1550 \mathrm{~K}$. This treatment removed the thin oxide layer and epitaxial $\mathrm{SiC}$ and resulted in the appearance of a sharp $(7 \times 7)$ superstructure RIIEED patterns [9]. Typical RIEED patterns taken from $\mathrm{Si}(111)-(7 \times 7)$ surfaces with [112] incidence are shown in Fig. 1a. Direct resistive heating of the Si crystal was employed. The substrate could be cooled to about $110 \mathrm{~K}$ by making thermal contact between the rotatable holder and a $\mathrm{LN}$ container.

Figure 1b shows another type of surface prepared by deposition at about 1.2 monolayer (ML) of $\mathrm{Au}$ on a $\mathrm{Si}$ surface with $(7 \times 7)$ superstructure. Au deposits were annealed for $0.5 \mathrm{~min}$ at about $950 \mathrm{~K}$ and then the temperature was gradually lowered to about $500 \mathrm{~K}$ during $3 \mathrm{~min}$. This type of surface showed a well-developed $(6 \times 6)$ Au superstructure RIIEED pattern $[7,10,11]$.

Indium was evaporated from stainless-steel crucibles and $\mathrm{Au}$ was evaporated from BN crucibles shielded by a water-cooled wall. Deposition rates between 0.01 and $0.1 \mathrm{~nm} / \mathrm{s}$ were used. The thickness of the growing films was measured with a quartz-crystal monitor converting the frequency change into a voltage signal.

The RHEED system was operated at $20 \mathrm{keV}$ and consisted of a triode electron gun, a 1-mm-diam beam-defining aperture, a magnetic focusing lens, and sets of magnetic deflection coils controlling the polar angle $\Theta$ of incidence of the electron beam. This angle could be adjusted with an accuracy of $\pm 0.05^{\circ}$. The azimuthal angle was adjusted relative to the Si RHEED pattern with an accuracy of $\pm 1^{\circ}$. The intensity of the specularly reflected beam was measured with aid of photodiode with a $0.8 \mathrm{~mm}$ diameter aperture attached to the fluorescent screen. The data from the photodiode and the quartz-crystal monitor were recorded both on a $X-Y$ recorder and stored in digital form by computer system (microcomputer PC-XT with IEEE-488 interface system). 


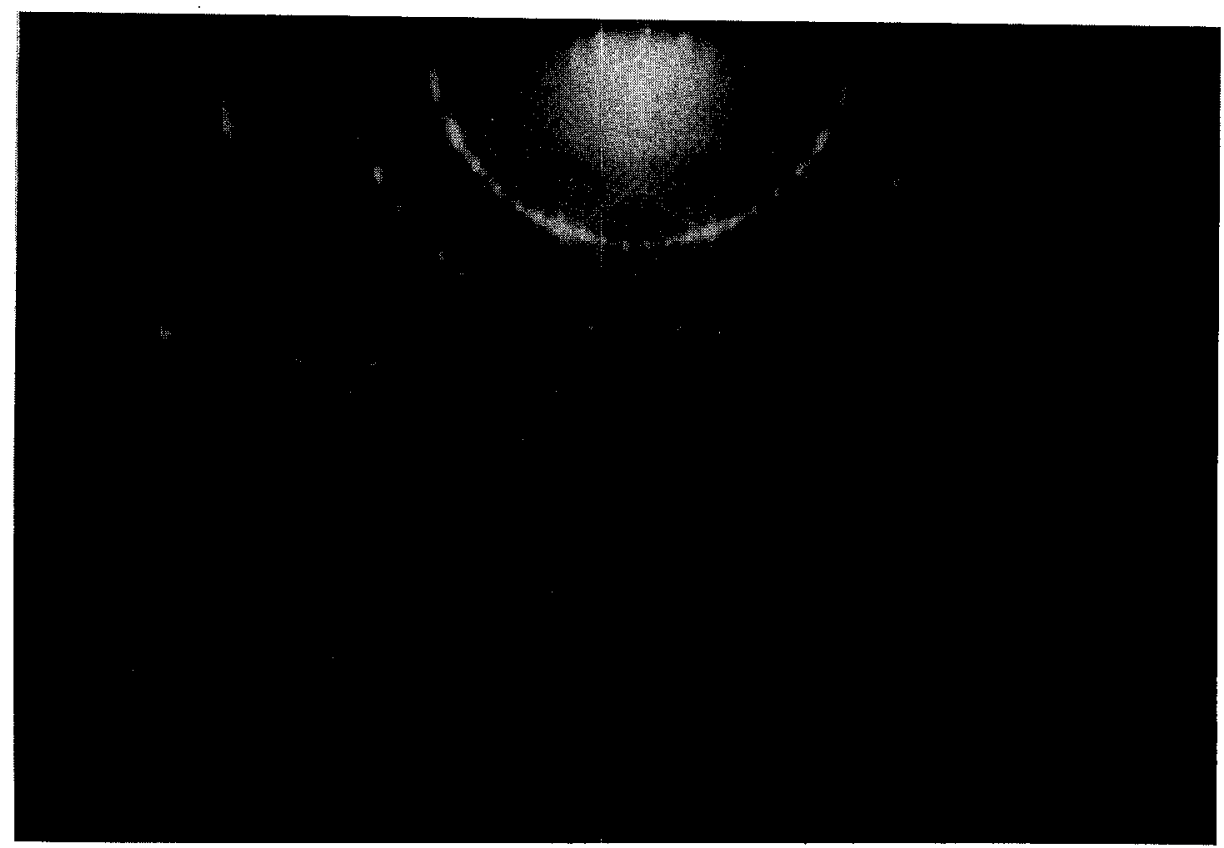

a

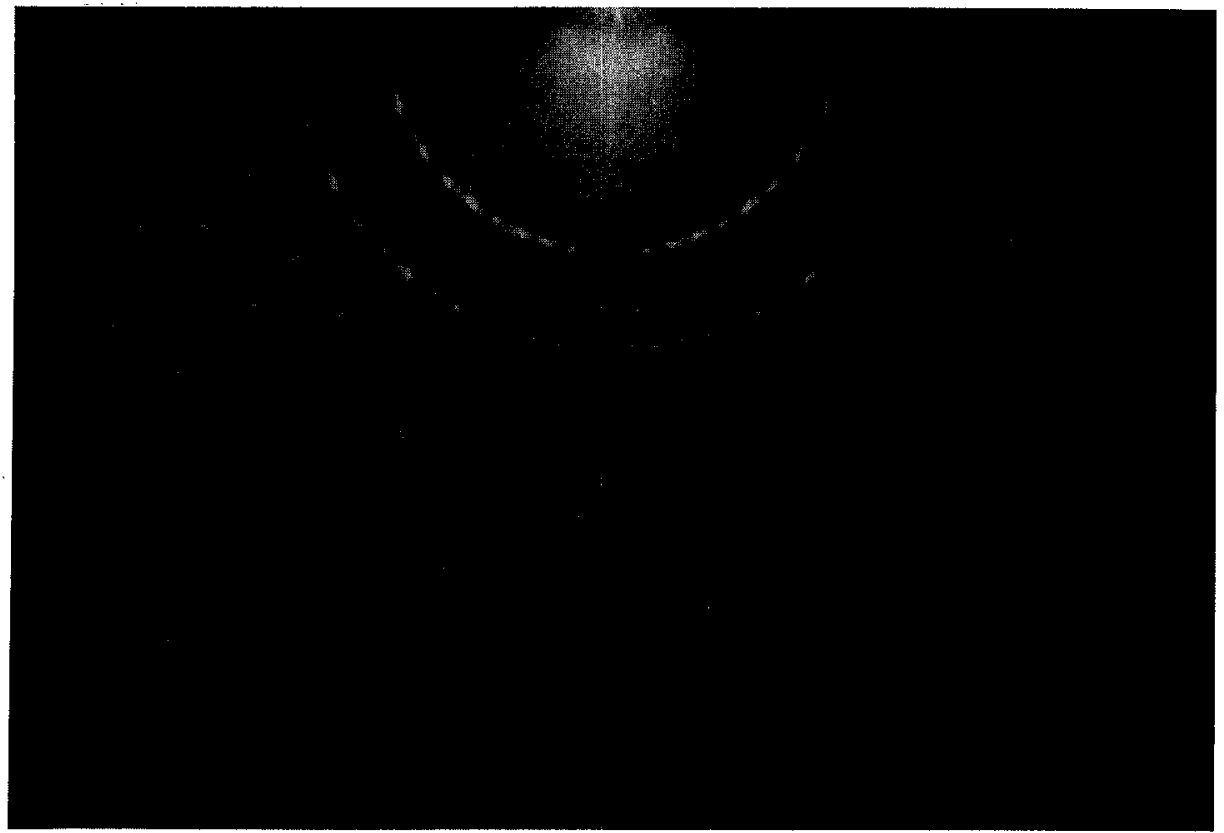

b

Fig. 1. RHEED patterns (a) taken from $\mathrm{Si}(111)-(7 \times 7)$ structure, azimuth of incidence [112]; (b) taken from $\mathrm{Si}(111)-(6 \times 6) \mathrm{Au}$ structure induced by Au. Electron beam energy is $20 \mathrm{keV}$, glancing angle is equal to $0.35^{\circ}$. 


\section{Results and discussion}

We observed RHEED specular beam oscillations for ultrathin metallic films of In during the growth on $\mathrm{Si}(111)-(7 \times 7) \mathrm{Si}(111)-(6 \times 6)$ Au substrates. A typical result for a RHEED specular beam intensity measured during the growth of In films on $\mathrm{Si}(111)-(7 \times 7)$ and $\mathrm{Si}(111)-(6 \times 6)$ Au surfaces at $110 \mathrm{~K}$ is shown in Fig. 2. The polar (glancing) angle $\Theta$ of the electron beam was equal to $0.30^{\circ}$ and azimuthal

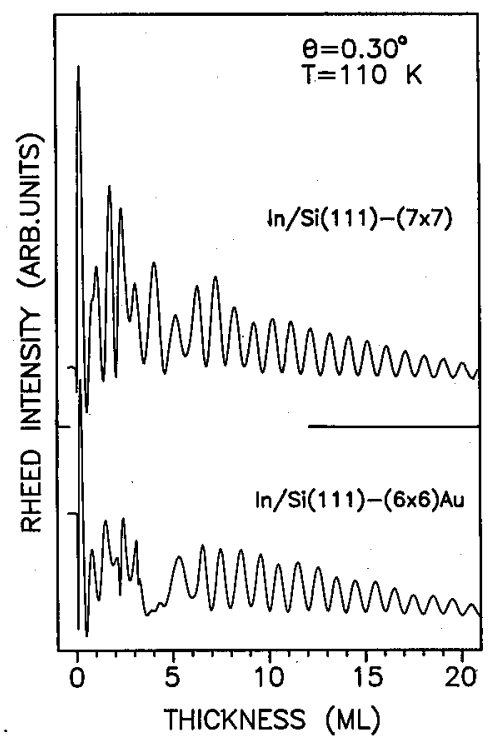

Fig. 2. RHEED specular beam intensity oscillations during the growth of In films on a clean $\mathrm{Si}(111)-(7 \times 7)$ surface and on $\mathrm{Si}(111)-(6 \times 6)$ Au surfaces at $110 \mathrm{~K}$. Electron beam energy is $20 \mathrm{keV}$, azimuth: $\mathrm{Si}[11 \overline{2}]$, polar (glancing) angle $\Theta=0.30^{\circ}$.

angle was chosen to be Si[112]. During the growth of the thin films on the pure Si(111) $-(7 \times 7)$ surface the oscillations became regular after the deposition of about $4 \mathrm{ML}$ of In (about $10 \AA$ ). This initial complicated structure of the RIIEED intensity oscillations is presumably caused by differences of the crystal structure of In and $\mathrm{Si}$. The irregularity of the oscillations in the initial stage of the growth have been also created by the interaction of the beam with Si crystalline substrate and the growing films. This suggests that In up to 4 ML thickness on clean $\mathrm{Si}(111)$ forms a highly disordered films and strongly compressed layer in the same orientation as the thicker layers which seem to grow from the thin layer by recrystallization. Then sharp streaks appear. This is illustrated in Fig. 3 which shows the RIIEED patterns of In layers on $\mathrm{Si}(111)-(7 \times 7)$ surfaces after deposition $4 \mathrm{ML}$. For $2 \mathrm{ML}$ of pure In films deposited on $\mathrm{Si}(111)-(7 \times 7)$ surface the diffuse streaks in a strong background were not observed. The orientation of the In layers was the same as that of the substrate, $\operatorname{In}(111) \| \mathrm{Si}(111)$, for the thin films deposited directly on $\mathrm{Si}(111)-(7 \times 7)$. When In grows on $\mathrm{Si}(111)-(6 \times 6) \mathrm{Au}$ surfaces, the regular oscillations are seen after 


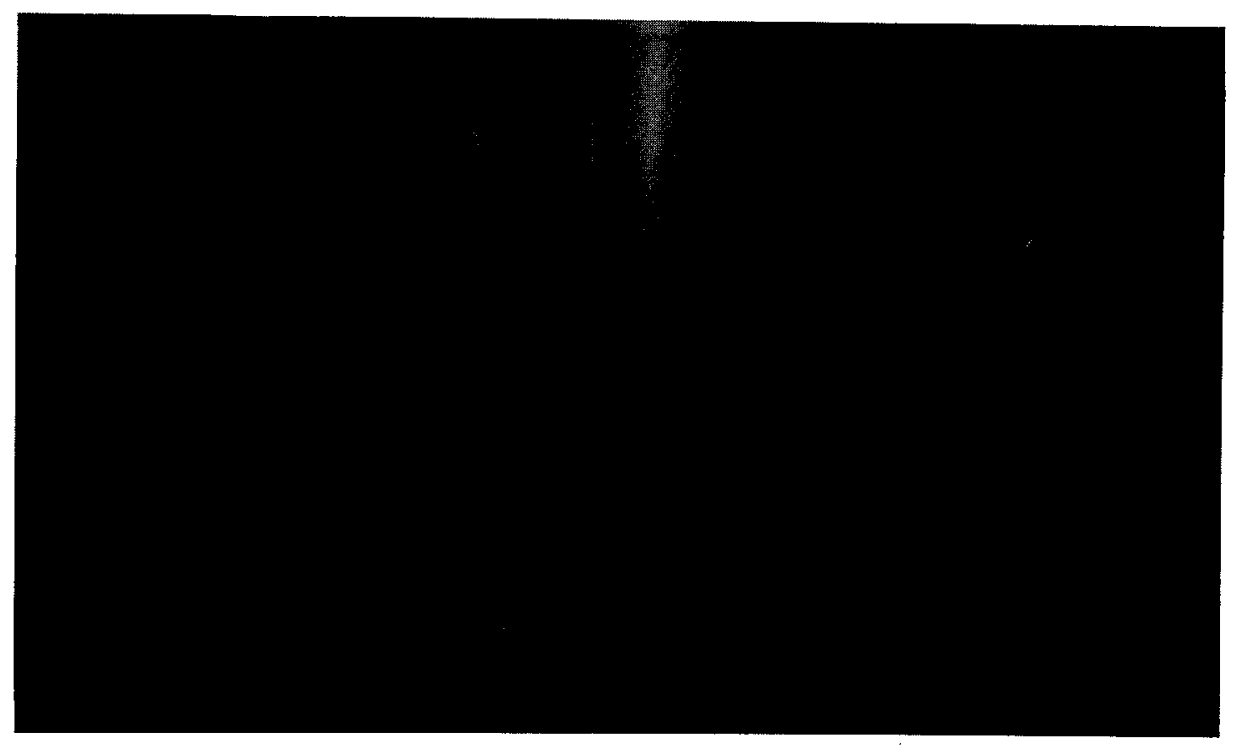

Fig. 3. RHEED patterns after deposition of the first $4 \mathrm{ML}$ of In on $\mathrm{Si}(111)-(7 \times 7)$ surfaces at $110 \mathrm{~K}$. Electron beam energy is $20 \mathrm{keV}$, azimuth: $\mathrm{Si}[112]$.

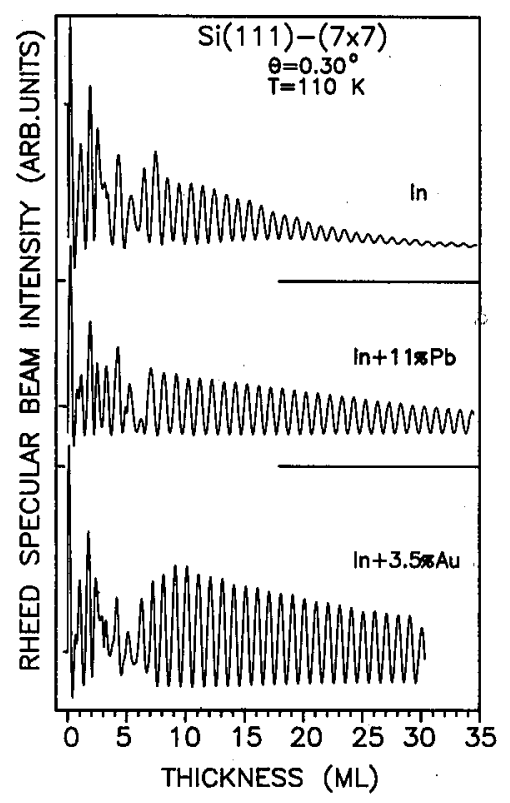

Fig. 4. RHEED specular beam intensity oscillations during growth of In+3.5\%Au and In $+11 \% \mathrm{~Pb}$ alloy films on a clean $\mathrm{Si}(111)-(7 \times 7)$ surface at $110 \mathrm{~K}$. Azimuth: $\mathrm{Si}[112]$, polar (glancing) angle $\Theta=0.30^{\circ}$. 
deposition of about $6 \mathrm{ML}$ of In.

For the In ultrathin films the intensity oscillations are strongly damped. Coevaporation of small amounts of $\mathrm{Au}$ or $\mathrm{Pb}$ enhanced strongly the RHEED intensity oscillations and the oscillations were observed over a large thickness range. This is shown in Fig. 4 in which $\mathrm{Au}$ and $\mathrm{Pb}$ was deposited simultaneously with In onto a $\mathrm{Si}(111)-(7 \times 7)$ surface. More than 100 periods of oscillations were recorded for In+3.5\% Au alloy films. This corresponds to a thickness of about $30 \mathrm{~nm}$.
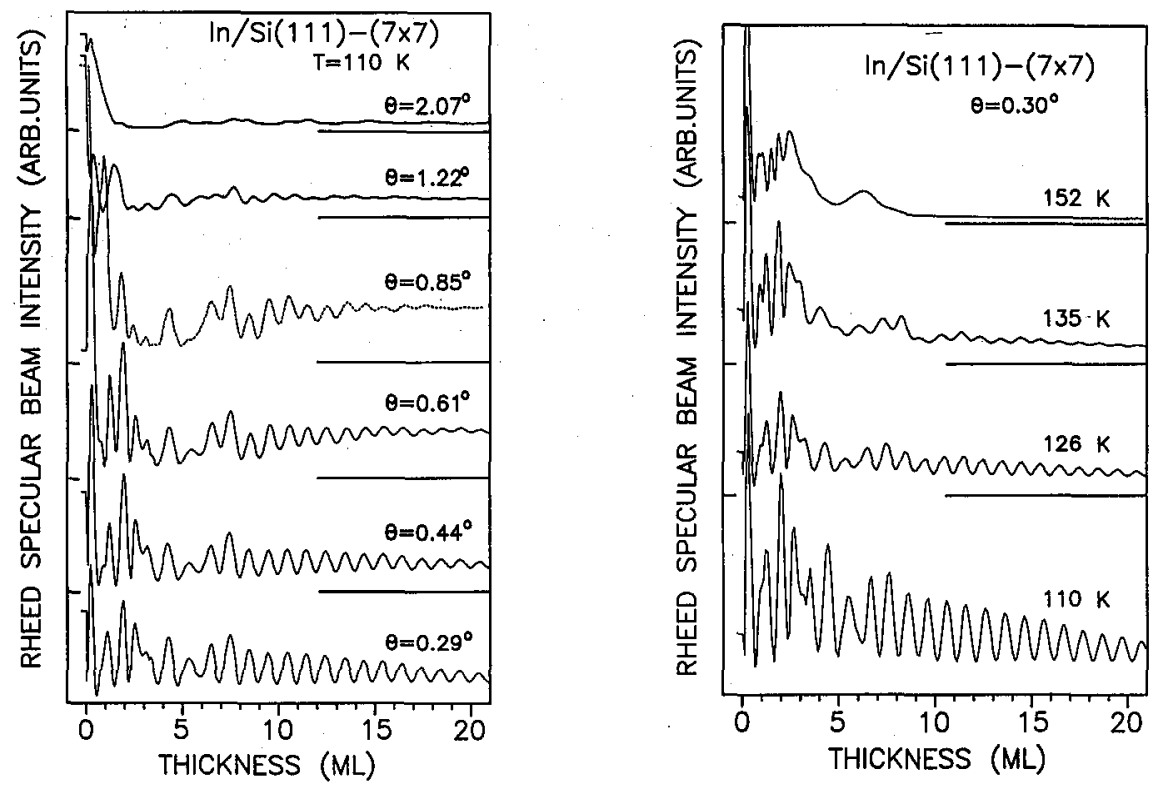

Fig. 5. RHEED intensity oscillations during the growth of In layers on a $\operatorname{Si}(111)-(7 \times 7)$ surface at $110 \mathrm{~K}$ for the indicated polar angle. Azimuth angle of the incident beam direction was set at $7^{\circ}$ from the $[11 \overline{2}]$ direction.

Fig. 6. RHEED specular beam intensity oscillations during the growth of In layers for different temperatures on clean $\mathrm{Si}(111)-(7 \times 7)$ substrates. Azimuth: $\operatorname{Si}[11 \overline{2}]$, electron beam energy $20 \mathrm{keV}$.

The RHEED specular beam intensity oscillations showed the strong glancing angle $\theta$ dependence. Figure 5 shows the intensity of the specular beam as a function of the thickness of the In layer for different glancing angle of the incident beam. The RIIEED intensities were measured at about $7^{\circ}$ from the [112] direction of the incident azimuth. With increasing glancing angle the sharp modulated streaks are observed.

RHEED intensity oscillations occur not only during the growth at $110 \mathrm{~K}$ but also at higher temperatures. Figure 6 shows the RIIEED intensity during the growth of the In layers on clean $\mathrm{Si}(111)-(7 \times 7)$ surfaces at different temperatures. However the amplitudes decrease with increasing temperature and no oscillations 
were seen above $150 \mathrm{~K}$. With increasing temperature the streaks become sharper. This suggests that we observed larger grain size growth of the indium films.

\section{Conclusions}

The results presented here should be of technological importance for the preparation of the ultrathin metallic films and for monitoring of their growth by means of the RIIEED technique. We have shown that ultrathin single-crystal films of In with good surfaces can be grown on the $\mathrm{Si}(111)$ surface at about $110 \mathrm{~K}$. The occurrence of the RHEED intensity oscillations during deposition of the In layers on $\mathrm{Si}(111)-(7 \times 7)$ and $\mathrm{Si}(111)-(6 \times 6) \mathrm{Au}$ surfaces indicates monolayer-by-monolayer growth (Frank-van der Merwe (FM) growth mechanism). The manner of preparation of In thin layers has a remarkable influence. By coevaporation of the other elements $(\mathrm{Au}$ or $\mathrm{Pb})$ the thickness range of the monolayer-by-monolayer growth of In films can be considerably extended.

\section{Acknowledgements}

This work was supported by the Ministry of National Education under grant No. II. 1.7/P/04/069.

\section{References}

[1] Reflection High Energy Electron Diffraction and Reflection Electron Imaging of Surfaces, Eds. P.K. Larsen, P.J. Dobson, NATO ASI series, Vol. 188, Plenum, New York 1988.

[2] J.J. Harris, B.A. Joyce, P.J. Dobson, Surf. Sci. 103, L90 (1981); 108, L444 (1981).

[3] C.E.C. Wood, Surf. Sci. 108, L441 (1981).

[4] S.T. Purcell, B. Heinrich, A.S. Arrott, Phys. Rev. B 35, 6458 (1987).

[5] C. Koziol, G. Lilienkamp, E. Bauer, Appl. Phys. Lett. 51, 901 (1987).

[6] M. Jałochowski, E. Bauer, Surf. Sci. 213, 556 (1989).

[7] M. Jałochowski, E. Bauer, J. Appl. Phys. 63, 4501 (1988).

[8] M. Jałochowski, M. Stróżak, M. Subotowicz, in Proc. 4th Conf. Surf. Phys. Lódź, Poland, 1989, Eds. R. Bacewicz, J. Rutkowski, R. Trykozko, Vol. 7, Publishing House of the Eódź University, Łódź 1990, p. 186.

[9] S. Ino, Jpn. J. Appl. Phys. 16, 891 (1977).

[10] A.K. Green, E. Bauer, Surf. Sci. 103, L127 (1981).

[11] G.le Lay, Surf. Sci. 132, 169 (1983). 